\title{
A Study on Relationship among Blade Camber Direction and Pitch Angle and Performance of a Small Straight-Blade Darrieus Wind Turbine by Using Scale Test Model and Gurney Flap
}

\author{
Tadakazu Tanino¹, Keisuke Hara', Ryo Yoshihara' ${ }^{1}$, Takeshi Miyaguni² \\ ${ }^{1}$ Advanced Engineering School, National Institute of Technology, Kurume College, Fukuoka, Japan \\ ${ }^{2}$ Department of Mechanical Systems Engineering, University of Kitakyushu, Fukuoka, Japan \\ Email: ttanino@kurume-nct.ac.jp
}

How to cite this paper: Tanino, T., Hara, K., Yoshihara, R. and Miyaguni, T. (2021) A Study on Relationship among Blade Camber Direction and Pitch Angle and Performance of a Small Straight-Blade Darrieus Wind Turbine by Using Scale Test Model and Gurney Flap. Journal of Flow Control, Measurement \& Visualization, 9, 28-44. https://doi.org/10.4236/jfcmv.2021.92003

Received: November 25, 2020

Accepted: March 23, 2021

Published: April 25, 2021

Copyright $\odot 2021$ by author(s) and Scientific Research Publishing Inc. This work is licensed under the Creative Commons Attribution International License (CC BY 4.0).

http://creativecommons.org/licenses/by/4.0/

\begin{abstract}
Straight-blade Darrieus vertical axis wind turbines are used as medium and small size wind turbine because of higher power output in vertical axis wind turbine (VAWT). In our previous study, the relationship between the performance and Reynolds number based on airfoil chord length had been investigated by using small-scale test models of lift-type VAWT, and the results showed that the performance of tested wind turbine models with small diameter was clearly lower than that of the large-scale field test machine, and its performance also varies significantly with the blade pitch angle. In this study, we focused on the performance of a small-scale straight-blade Darrieus VAWT, the relationship among the blade airfoil camber direction and the pitch angle, and the performance of the small-scale VAWT was examined experimentally by using a small-scale VAWT test model with Gurney flap which was a small flat plate. Gurney flaps with its height $h$, as a ratio to the blade chord length $\mathrm{c}$, $h / c=0.036$ to 0.055 , were attached to the blades of the VAWT test model, in addition, the attaching direction of the Gurney flap on the blade was examined for both inward and outward of the rotor, and the pitch angle was also examined for a range of -5 to 10 degrees. These results are discussed comparing with the result of the VAWT without Gurney flap and considering the numerical results for the single blade with/without the Gurney flap. The results showed that the performance of the tested VAWT was reversed between the inward and outward Gurney flaps around a pitch angle of 10 degrees. That is, the inward Gurney flap was superior at a pitch angle of less than 10 degrees, while the outward Gurney flap was effective at a pitch angle of more than 10 degrees. Furthermore, for the tested small-scale VAWT model, the
\end{abstract}


optimum pitch angle was about 5 degrees, and the inward and shorter Gurney flap showed higher power performance of the VAWT under this pitch angle condition.

\section{Keywords}

Darrieus VAWT, Gurney Flap, Camber Direction, Pitch Angle, Power Performance

\section{Introduction}

Recently, for the effective utilization of wind energy, various research and development activities such as floating offshore wind power generation using largescale wind turbines and wind environment assessment. In addition, in near future for the use of various types of renewable energy, promotion of local production for local consumption of electricity combining with smart grid demonstration projects in urban areas is being carried out. If the use of this local generated renewable energy promoted, also the use of medium and small wind turbines will be effective. Therefore, it is important to improve the safety and performance of these wind turbines in the future.

So far, we have studied the relationship between the Reynolds number and the performance of the straight-blade Darrieus vertical axis wind turbines (VAWTs), which are expected as medium and small wind turbines with high power output characteristics [1] [2]. In this study, field tests for the practical application of the VAWT and wind tunnel test using small-scale test models of the VAWT were conducted. The results showed that the wind turbine performance of the smallscale test model with a diameter of $0.38 \mathrm{~m}$ was obviously lower than that of the large-scale field test machine with a diameter of $2.6 \mathrm{~m}$ [2]. In relation to this, the performance of straight-blade Darrieus VAWTs with different diameters ranging from 0.30 to $0.45 \mathrm{~m}$ had been examined by Longhuan et al. [3]. It was showed that larger diameter showed higher maximum performance of VAWT while smaller diameter had better self-starting performance. These results suggest that the performance of the VAWTs has different characteristics at different scale.

The relationship between the performance of several types of Darrieus VAWTs and the camber of blade airfoils has been experimentally studied by Hara et al. [4], Ejiri et al. [5], and Longhuan et al. using small-scale Darrieus VAWT of less than $1 \mathrm{~m}$ in rotor diameter. Hara et al. had compared NACA0018 symmetrical airfoil with cambered airfoil, which was transformed by conformal mapping method between curvilinear and parallel flows, and showed that the cambered airfoil of concave-in configuration had higher performance of the power coefficient. Ejiri et al. had compared NACA0012 symmetrical airfoil with NACA4412 cambered airfoil and showed that the cambered airfoil of concave-out configuration had higher performance of the maximum power coefficient. In addition, Longhuan et al. [3] had compared NACA0021 symmetrical airfoil with DU06W200 
and NACA4415 cambered airfoils, and reported that DU06W200 cambered airfoil of concave-in configuration showed higher performance of the power coefficient, while NACA4415 cambered airfoil did not show sufficient performance, but also mentioned that their result was different from the analytical result of Kirke et al. [6] that NACA4415 airfoil showed superior performance than NACA0015 airfoil at low speed. Thus, regarding the relationship between the blade camber direction and the performance of small-scale Darrieus VAWT, the results could differ when the airfoil shape and the experimental environment, etc. are just slightly different. Therefore, from the perspective of accumulating data on the performance and the geometrical conditions such as airfoil shape for Darrieus VAWTs, it is hoped that more research reports based on experiments will be published in the future.

Moreover, regarding the application of Gurney flaps to straight-blade Darrieus wind turbines, Haitian et al. [7] [8] and Yan et al. [9] also conducted detailed numerical analysis on straight-blade Darrieus VAWTs with diameters of more than $1 \mathrm{~m}$ and a pitch angle of 0 degrees. Haitian et al. [7] showed that the performance of the VAWT is better by applying the Gurney flap to NACA0021 airfoil, regardless of its attaching direction, compared to the clean airfoil. Yan et al. [9] showed that there is a clear difference in the performance of the VAWT with NACA0018 airfoils even between $h / c=0.04$ and $h / c=0.05$ of inward Gurney flaps. Their results are very interesting because it is different from our results using a small-scale straight-blade Darrieus VAWT as described later in section 3.3. We think that this is due to the size of the wind turbine rotor and the Reynolds number based on blade chord length.

Therefore, focusing on small-scale lift-type VAWTs, we conduct experimental studies on the effect of Gurney flaps attached to the wind turbine blades on the performance of a small-scale VAWT. In this study, we investigated the effects of the blade camber direction and the pitch angle on the performance of the VAWT by using Gurney flaps. That is, as a simple way to obtain the same effect as the blade camber, Gurney flaps were attached to the trailing edge of blade with a symmetrical airfoil as shown in Figure 1 in the next chapter, and the effect of the flap height and direction, which relate to the degree and direction of camber, and the effect of the blade pitch angle on the performance of the small-scale VAWT were investigated. The Gurney flap has a simple shape of a projecting tab attached to the trailing edge of the blade and perpendicular to the flow as shown in Figure 1. This Gurney flap causes a difference in the flow velocity between the upper and lower surfaces of the blade, and the same effect as blade camber can be obtained. The degree of the camber effect can be changed easily by changing the flap height.

\section{Lift Enhancing Effect of Gurney Flap}

\subsection{Numerical Analysis of NACA0018 Airfoil with Gurney Flap}

NACA0018 airfoil with $110 \mathrm{~mm}$ chord length was used as the blade section pro- 
file of the small-scale VAWT test model. In order to understand the lift enhancing effect of the Gurney flap used on the blade of VAWT test model, two-dimensional numerical analysis was performed on the NACA0018 airfoil with and without the Gurney flaps.

Figure 1 shows the cross-sectional shape and size of the airfoil with a Gurney flap of $6 \mathrm{~mm}$ height. Table 1 shows the analysis conditions such as the Gurney flap size (flap height) and the angle of attack. The Reynolds number is set to Re $=8.8 \times 10^{4}$, considering the range of Reynolds number $5.1 \times 10^{4}-10.3 \times 10^{4}$ (one to two times the Reynolds number based on the chord length at the tip speed ratio $\lambda=1$ ) near the operating point where the tested VAWT model shows its maximum power coefficient. This value of Reynolds number is relatively small due to the small size of the VAWT model.

The pimpleFoam as a solver was used. This solver is a transient solver for incompressible turbulent flow in the general-purpose fluid analysis software package OpenFOAM Ver.2.1.1. The $k$ - $\omega$ SST model was chosen as the turbulence model.

\subsection{Numerical Analysis Results}

Figure 2 shows an example of the calculation area and mesh. The size of the calculation area is $1500 \mathrm{~mm} \times 2000 \mathrm{~mm}$, and the minimum mesh size on the blade surface was set $0.4 \mathrm{~mm}$. However, in the area away from the blade surface, a coarse mesh was applied to reduce the computational load.

Figure 3 shows the relationship between the time averaged lift coefficient $C_{L}$ obtained from the numerical analysis results and the angle of attack AOA. Figure 4 shows the relationship between the time averaged drag coefficient $C_{D}$ and the angle of attack, as in Figure 3. In these figures, the results with and without the Gurney flaps are compared. For the case without a Gurney flap $(h / c=0.00)$, the experimental results [10] under the condition of low Reynolds number

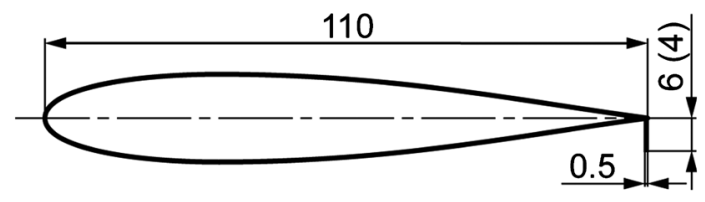

Figure 1. Airfoil section with Gurney flap $6 \mathrm{~mm}(\mathrm{NACA0018}, h / c=0.055)$.

Table 1. Numerical analysis conditions.

\begin{tabular}{ccc}
\hline & Airfoil Type & NACA0018 \\
Airfoil specifications & Chord length: $c$ & $110 \mathrm{~mm}$ \\
& Flap height: $h$ & $0 \mathrm{~mm}, 4 \mathrm{~mm}, 6 \mathrm{~mm}$ \\
\hline \multirow{2}{*}{$\begin{array}{c}\text { Flow and airfoil setting } \\
\text { conditions }\end{array}$} & Inlet velocity: $V$ & $12 \mathrm{~m} / \mathrm{s}$ \\
& Reynolds number & $8.8 \times 10^{4}$ \\
& $h / c$ & $0.0,0.036,0.055$ \\
& Range of angle of attack (AOA) & $-5^{\circ}-10^{\circ}$ \\
\hline
\end{tabular}




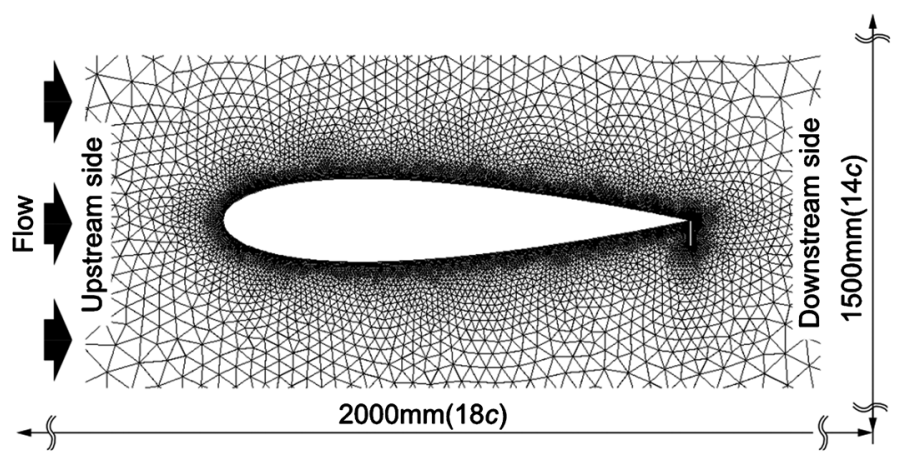

Figure 2. Numerical region and mesh (NACA0018 with Gurney flap $h / c=0.055$ ).

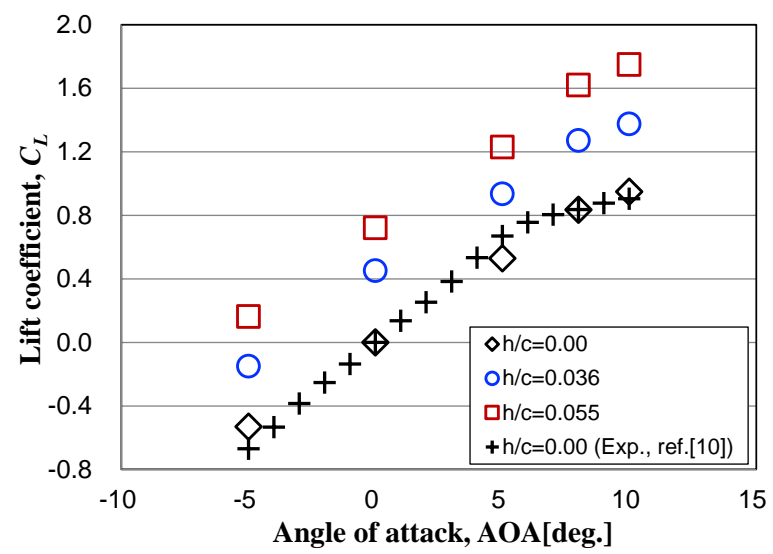

Figure 3. Comparison of $C_{L}$-AOA characteristics from CFD results with/without Gurney flaps (NACA0018, $\left.\mathrm{Re}=8.8 \times 10^{4}\right)$.

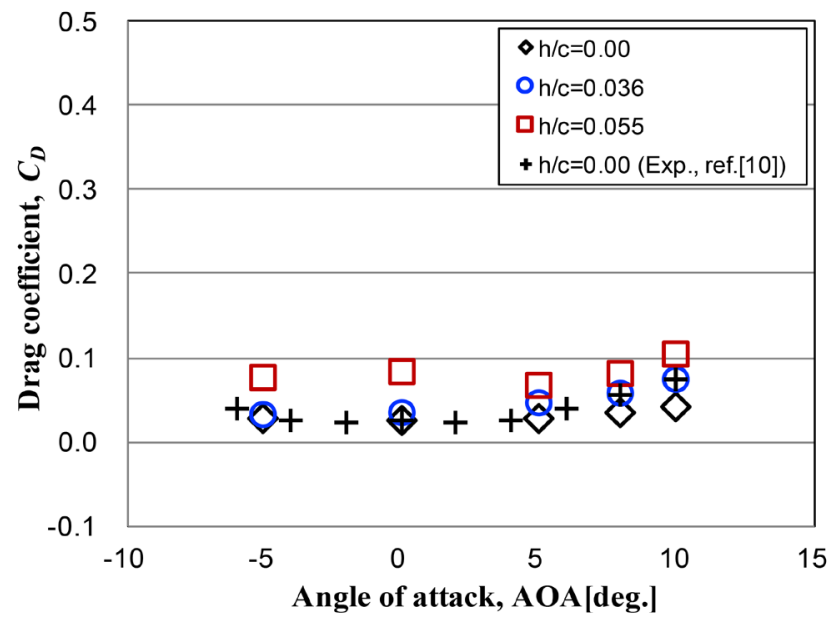

Figure 4. Comparison of $C_{D}$ - AOA characteristics from CFD results with/without Gurney flaps (NACA0018, $\operatorname{Re}=8.8 \times 10^{4}$ ).

$1.0 \times 10^{5}$ close to the Reynolds number in this study, which are reported by Boutilier and Yarusevych, are also shown for comparison. Comparing the numerical results and the experimental results [10], our numerical results are considered to be reasonable. In addition, Figure 5 shows the relationship between the time averaged lift coefficient increment $\Delta C_{L}$ and the angle of attack. Note that $\Delta C_{L}$ is the 


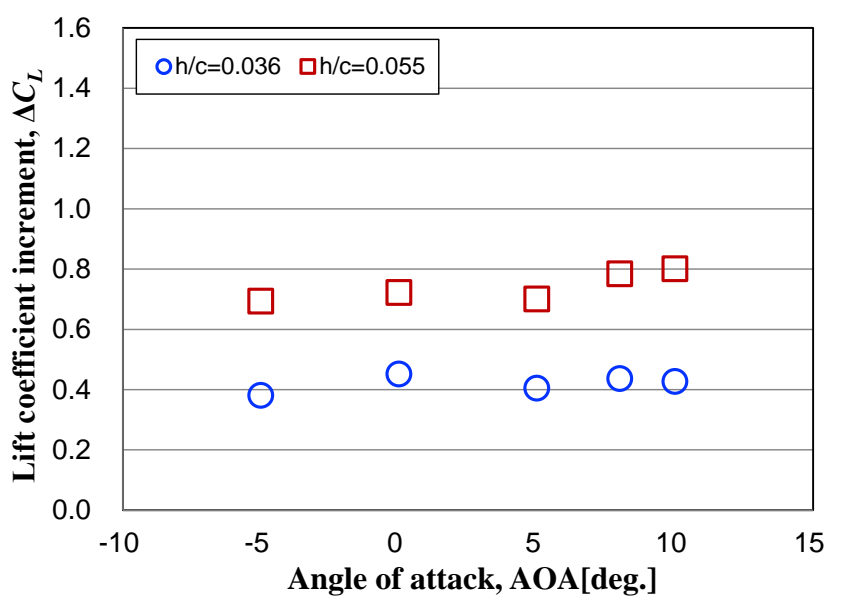

Figure 5. Comparison of $\Delta C_{L}$-AOA characteristics from CFD results with Gurney flaps $\left(\mathrm{NACA0018}, \mathrm{Re}=8.8 \times 10^{4}\right)$.

difference in lift coefficient of the blade between with and without the Gurney flaps.

In Figure 3, as the $h / c$ increases, the lift coefficient $C_{L}$ clearly increases at each angle of attack up to the point of maximum lift coefficient ( $\mathrm{AOA}=10$ deg.). From the increase in lift coefficient $\Delta C_{L}$ due to the Gurney flap shown in Figure 5, $\Delta C_{L}$ is almost constant for each flap height and $\Delta C_{L \text { ave }}=0.42$ for $h / c=0.036$ and $\Delta C_{L \text { ave }}=0.74$ for $h / c=0.055$. These results show that the Gurney flap greatly improves the lift characteristics of NACA0018 symmetrical airfoil. On the other hand, as shown in Figure 4, in the range of AOA of -5 to 10 degrees, the increase in drag coefficient by the Gurney flaps is clearly smaller than that in lift coefficient in Figure 3. The increase in drag coefficient is $\Delta C_{D \text { ave }}=0.02$ for $h / c=$ 0.036 and $\Delta C_{D \text { ave }}=0.05$ for $h / c=0.055$, which is less than one tenth of the increase in lift coefficient.

In addition, as shown in Figure 3, the angle of attack near the stall point does not shift to smaller value even if the Gurney flaps are applied. It is thought that this is because NACA0018 airfoil is relatively thick and the radius of curvature of the leading edge is large. In contrast, for thin airfoil such as NACA0011 with the small leading edge radius, the angle of attack near the stall point tends to be smaller when a Gurney flap is applied to the airfoil [11]. The results in Figure 3 also suggest that the NACA0018 airfoil is able to maintain the higher lift characteristics in the equivalent range of the angle of attack to the clean airfoil in the relatively low Reynolds number flow even when the Gurney flaps are applied.

From the above results, it can be said that the Gurney flaps applied to the VAWT test model clearly enhance the aerodynamic characteristics of the blades and the Gurney flaps have the effects corresponding to applying an airfoil camber or a pitch angle. Therefore, assuming that the Gurney flaps give the same effects on the VAWT blades, the power performance tests of a small-scale VAWT test model with the Gurney flaps were conducted as described in the next chapter. 


\section{Experimental Test of Straight-Blade Darrieus VAWT}

\subsection{Tested Wind Turbine Models and Test Conditions}

Figure 6 shows the small-scale VAWT test model using the blades with a Gurney flap. The tested VAWT model was a three-blade wind turbine with a diameter $D$ of $380 \mathrm{~mm}$. The axial length $L$ of the rotor is $210 \mathrm{~mm}$.

The airfoil is NACA0018 as shown in Figure 1, and the chord length is $c=$ $110 \mathrm{~mm}$. The Reynolds number is about $5.1 \times 10^{4}$ when the reference length scale and speed are the chord length of the airfoil and the inlet wind speed in the performance test respectively.

Figure 7 illustrates the conditions for the blade mounting position on the rotor arm and the pitch angle of the blade. The blade was fixed to the rotor arm at the maximum thickness position of the airfoil. The pitch angle is defined as the inclination angle of the center line of the blade without the Gurney flap but not the inclination of the straight line from the leading edge of the blade to the tip of the flap.

Table 2 shows a list of flap conditions with flap height $h$, the ratio of height and blade chord $h / c$ and flap attaching direction. As shown in the leftmost column of Table 2, each flap condition is labeled, symmetrical blade without the Gurney flap is designated NG0 as the reference condition. For the blades with the flaps, each label is represented by a combination of the following symbols and flap height. "G" represents the Gurney flap, the flap attachment direction is represented by "I" when the flap is facing inward of the rotor and "O" when the

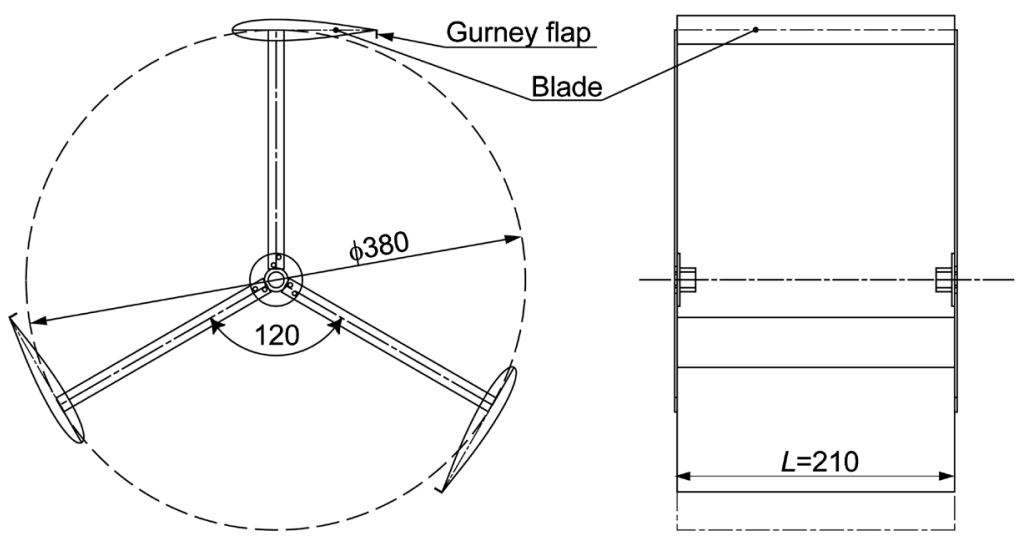

Figure 6. Schematic of straight-blade Darrieus VAWT test model (Gurney flap on inner side, $h / c=0.055$ ).

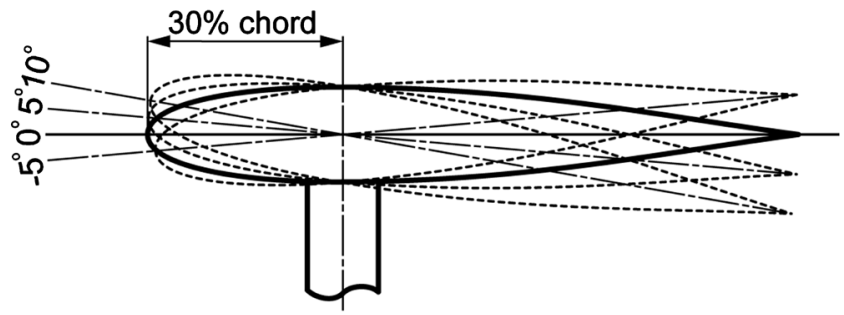

Figure 7. Blade mounting position and pitch angle conditions of VAWT test model. 
flap is facing outward.

For each of the VAWT test models under the five different flap conditions shown in Table 2, with the conditions of pitch angles of $-5,0,5$ and 10 degrees in Figure 7, a total of twenty cases of power performance tests were conducted.

\subsection{Power Performance Test Method}

Figure 8 shows the schematic diagram of the experimental setup for the power performance test of the small-scale VAWT test model. The simple wind tunnel used for this experiment is a small blower type wind tunnel with a cross section of $680 \mathrm{~mm} \times 680 \mathrm{~mm}$ at the outlet. We have not been able to measure turbulence intensity of the wind tunnel. However, in order to rectify the flow at the exit of the wind tunnel, two $\varphi 0.14 \mathrm{~mm}$ wire meshes with aperture ratio $60 \%$, a honeycomb grid with a cell size of $6.35 \mathrm{~mm}$, and a thin household non-woven filter were installed at the maximum cross section of the wind tunnel.

The VAWT test model was installed at the position where the center of the rotor shaft was $500 \mathrm{~mm}$ downstream from the outlet of the wind tunnel. A torque/rotation detector (SS-050 and MP-981, Ono Sokki Co., Ltd.) and a rotation control motor (P50B05020DXS00, Sanyo Denki Co., Ltd.) were connected to the shaft of the VAWT test model. Figure 9 shows a photograph of the VAWT test model installed in the test section downstream of the wind tunnel.

The wind speed in the power performance test was measured using a pitot tube mounted at the wind tunnel exit shown in Figure 8. The differential pressure

Table 2. Combinations of flap height ratio of height to airfoil chord and flap attaching direction.

\begin{tabular}{cccc}
\hline Label of blade & Flap height $\boldsymbol{h}$ & Height-chord ratio $h / c$ Flap attaching direction \\
\hline $\mathrm{NG} 0$ & $0 \mathrm{~mm}$ & 0.00 & - \\
GI4 & $4 \mathrm{~mm}$ & 0.036 & Inward \\
Inward & Outward \\
GI6 & $6 \mathrm{~mm}$ & 0.055 & Outward \\
\hline
\end{tabular}

Figure 8. Schematic diagram of test section for power performance test of the small-scale VAWT test model. 


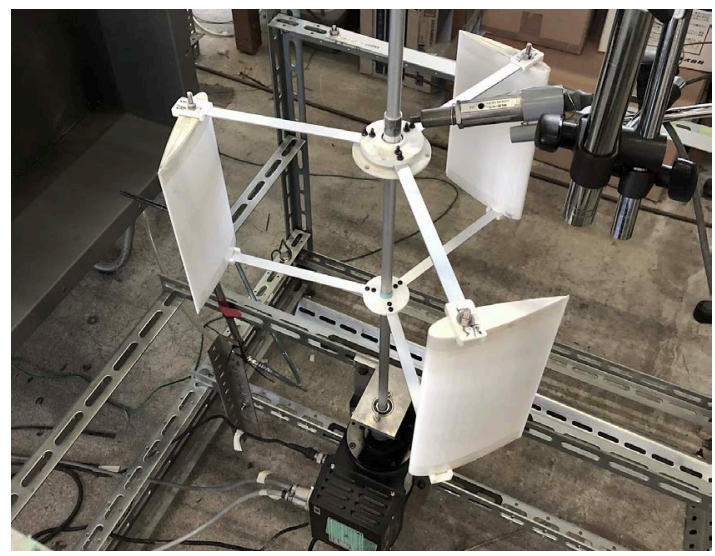

Figure 9. Photograph of the VAWT test model in the test section downstream of the wind tunnel.

of the pitot tube was measured using a digital differential pressure gauge (Manoace 140, Sayama Trading Co., Ltd.).

For the power performance testing, the inlet wind speed was set at $7 \mathrm{~m} / \mathrm{s}$, the rotation speed of VAWT test model was gradually reduced from the condition near no load operating point, and the torque and rotation speed were measured each time. In order to evaluate the aerodynamic torque only acting on the blades as accurately as possible, the shaft friction torque was measured under the conditions of only the rotor shaft and arms (without blades) as a preliminary experiment. The blade aerodynamic torque was obtained by correcting the torque measured in the power performance test by subtracting the axial friction torque. In addition, since the torque values of the small-scale VAWT test model are very small, the power performance tests for all the conditions shown in Figure 7 and Table 2 were carried out continuously at one time in order to reduce the influence of drift errors in the torque detector. The power performance test was measured three times for each condition. The average value was obtained from the measured torque and rotation speed.

The tip speed ratio $\lambda$ and the power coefficient $C_{p}$, defined in the Equations (1) and (2), were used to evaluate the performance of the VAWT test model. $\lambda$ and $C_{p}$ are the dimensionless parameters of rotation speed and power output based on the inlet wind speed and rotor swept area, respectively.

Tip speed ratio:

$$
\lambda=\frac{r \omega}{V} .
$$

Power coefficient:

$$
C p=\frac{T \omega}{\frac{1}{2} \rho V^{3} A} .
$$

where $r$ is the rotor radius, $\omega$ is the rotation angular velocity, $V$ is the inlet wind speed, $T$ is the shaft torque, $\rho$ is the air density and $A(=D \times L)$ is the rotor swept area. 


\subsection{Power Performance Test Results and Discussion}

Figures 10-13 show the performance curves for pitch angles of $0,5,10$ and -5 degrees, respectively. In each figure, the horizontal axis is the tip speed ratio $\lambda$ and the vertical axis is the power coefficient $C_{p}$, comparing the five conditions (NG0, GI4, GI6, GO4, and GO6) of the Gurney flap shown in Table 2.

Overall, from the comparison of Figures 10-13, the best power performance is shown in the condition of the pitch angle 5 degrees (Figure 11). Since the tested wind turbine is a small-scale model, the highest power coefficient is about 0.13 and the maximum tip speed ratio is about 1.6. These values are not sufficiently high. This may be due to the small size of tested wind turbine model and the difficulty in measuring the accurate shaft friction torque under the wind force acting on the blades and so on. Therefore, we think that these values are evaluated a little lower than the actual values. In addition, in Figures 10-12, the maximum tip speed ratio exceeds 1 , this may be because that the small-scale Darrieus VAWT is also driven by not only drag-force but lift-force.

First, in the case of pitch angle 0 degrees without the flap (NG0) shown in Figure 10, the power coefficient peaks near a tip speed ratio $\lambda=1$ and the maximum value of power coefficient is $C p_{\max }=0.068$. On the other hand, for

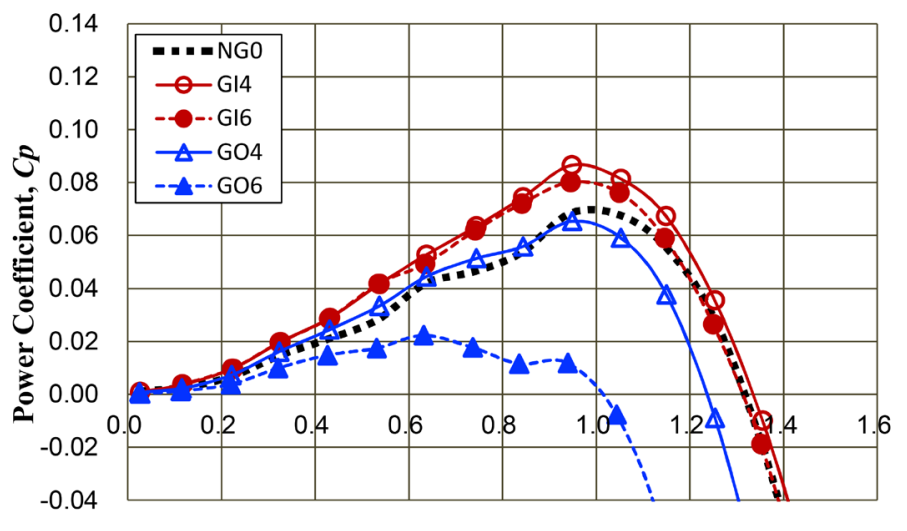

Tip Speed Ratio, $\lambda$

Figure 10. Performance curves in cases of pitch angle 0 degrees.

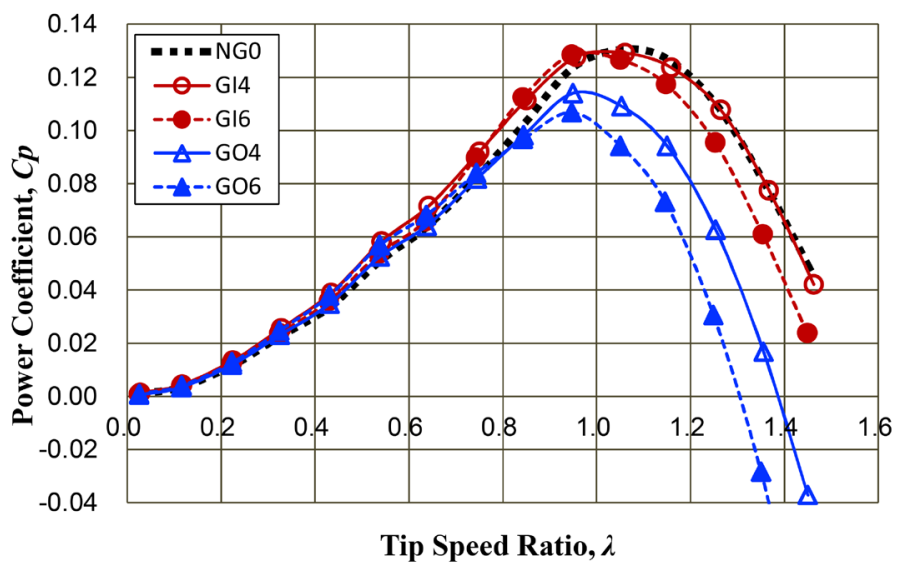

Figure 11. Performance curves in cases of pitch angle 5 degrees. 


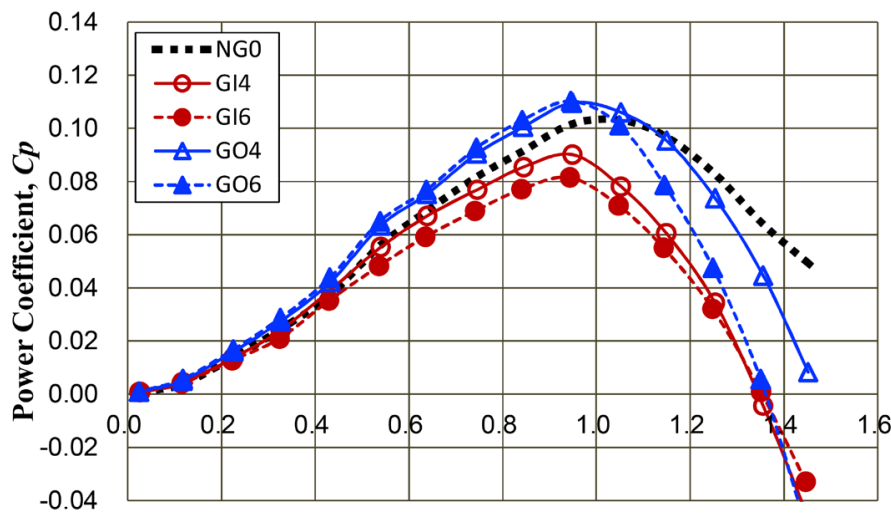

Tip Speed Ratio, $\lambda$

Figure 12. Performance curves in cases of pitch angle 10 degrees.

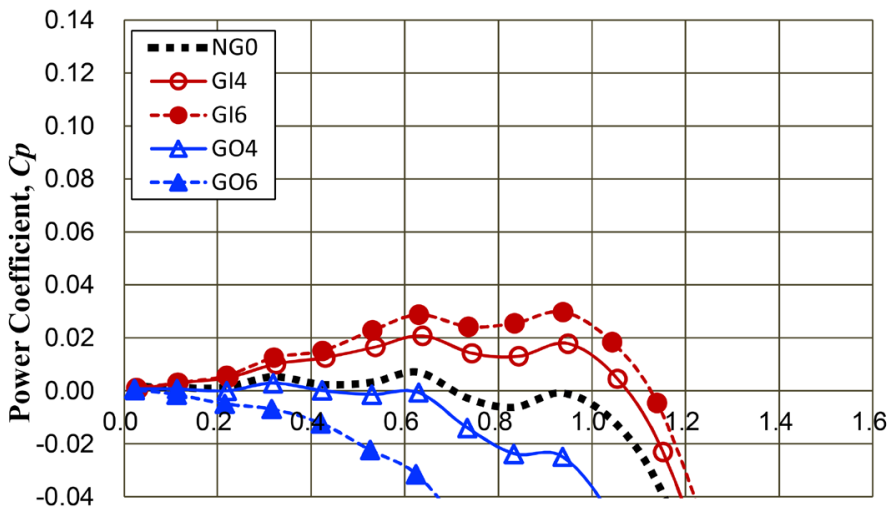

Tip Speed Ratio, $\lambda$

Figure 13. Performance curves in cases of pitch angle -5 degrees.

GI4 and GI6 with the Gurney flaps attached facing inward of the rotor, the power coefficients are higher in the low tip speed ratio region up to around $\lambda=1.2$ compared to that of NG0 with no flap. These maximum values are $C p_{\max }=0.08$ to 0.087 , which are also higher than that of NG0. In addition, in the region of higher tip speed ratio than the peak point of performance curve, the performance curves of GI4 and GI6 are approaching the curve of NG0. Comparing GI4 and GI6 with different flap heights, the performance curves of both are almost equal in the range of lower tip speed ratio than the maximum power coefficient point, but the power coefficient of GI4 with the shorter flap is slightly higher than that of than GI6 in the higher tip speed ratio side.

On the other hand, the maximum power coefficients of both GO4 and GO6 with the flaps outward of the rotor are lower when compared to that of NG0. The power coefficient of GO4, which flap is short, varies in much the same way as that of NG0 from the low tip speed ratio side to the point of maximum power coefficient. In the higher tip speed ratio side, the power coefficient of GO4 is lower than that of NG0. For GO6, which has the longer flap, the power performance is even lower. That is, the power coefficient varies below 0.02 over the entire range of tip speed ratio. The power coefficient peaks at about $\lambda=0.6$ and the 
peak position moves to the lower side in tip speed ratio.

Next, for the pitch angle of 5 degrees shown in Figure 11, the power performance is clearly higher for all the flap conditions, including NG0, than for the pitch angle of 0 degrees in Figure 10. For the case with no flap (NG0), the power coefficient reaches a peak value of $C p_{\max }=0.13$ at around $\lambda=1.05$ which exceeds 1 and this maximum value is about twice that in the case of NG0 with the pitch angle 0 degrees.

In the cases of inward facing flaps (GI4, GI6), the maximum value of the power coefficient is almost equal to that of NG0 without the flaps. In the range below the tip speed ratio where the power coefficients reach their peak values, these power coefficients are higher than that of NG0. For GI4, which has the shorter flap, the power coefficient reaches its peak value at almost the same tip speed ratio as NG0. In addition, GI4 shows the slightly wider range of tip speed ratio, in which the power coefficient is as high as its maximum value, than NG0. For the tip speed ratio range higher than where the power coefficient reaches its peak, the performance curve of GI4 almost corresponds to that of NG0. On the other hand, in the case of GI6 with the longer flap, the tip speed ratio, where the power coefficient peaks, is around $\lambda=1$ which is slightly lower than that in the case of NG0. In the tip speed ratio $\lambda>1$, the power coefficient of GI6 is lower than that of NG0 and GI4 and the performance curve of GI6 has a slightly sharper peak than that of NG0.

When the flaps are attached facing outward (GO4, GO6), the power coefficients for GO4 and GO6 are almost equal to or slightly higher than that of NG0 for the lower tip speed ratio $\lambda<0.8$. However, for the higher tip speed ratio above 0.8 , the power coefficients of both GO4 and GO6 are obviously lower than that of NG0. The performance curves of GO4 and GO6 reach their maximum peak values at the tip speed ratio below $\lambda=1$. The maximum power coefficient of GO4 with the shorter flap is $C p_{\max }=0.114$ and that of GO6 with the longer flap is even lower $C p_{\max }=0.107$. In the higher tip speed ratio side than the peak position of the performance curve, as the tip speed ratio increases, the power coefficients of both GO4 and GO6 apparently decrease compared to that of NG0.

Then, for the large pitch angle of 10 degrees shown in Figure 12, when no flaps are added (NG0), the power performance is inferior to that for the pitch angle of 5 degrees in Figure 11 but better than that for the pitch angle of 0 degrees in Figure 10. The maximum power coefficient is $C p_{\max }=0.102$ near the tip speed ratio of 1 . However, for the cases with the flaps at the pitch angle of 10 degrees shown in Figure 12, the relationship between the flap attaching direction and the power performance is reversed from the results at the pitch angles of 0 and 5 degrees shown in Figure 10 and Figure 11. That is, for the pitch angle of 10 degrees, the power performance is higher when the flap is attached outward of the rotor than when the flap is attached inward of the rotor. GO4 and GO6 with outward facing flaps show higher power coefficients than NG0 in a range lower than the tip speed ratio of the peak power coefficient and the maximum 
power coefficients of both GO4 and GO6 are $C p_{\max }=0.11$. However, the peak position of performance curve slightly moves to lower value of a tip speed ratio around $\lambda=0.95$.

On the other hand, GI4 and GI6 with inward facing flaps show lower maximum power coefficient $C p_{\max }$ of 0.09 and 0.08, respectively, and these performance curves are equal or lower than that of NG0 even in the low tip speed ratio region before the performance curves reach its peaks. Focusing on the flap height, it is shown that the shorter flaps show better power performance than the longer flaps regardless of inward or outward flap direction.

From the results shown in Figures 10-12, there is a clear tendency for the power performance to increase or decrease by applying the Gurney flaps. Especially in the low speed ratio range, it is clear that the appropriate flap can improve the power performance of the tested small-scale VAWT. In addition, the effective attached direction of the flap is inward facing direction for the performance of the VAWT. It is considered that the improvement effects on the power performance of GI4 and GI6 (inward facing flaps) in the low tip speed ratio in Figure 10 and Figure 11 is concerned with that the lift characteristics is improved by the Gurney flap shown in Figure 3. Even with the Gurney flap, the high lift characteristics is maintained up to the same angle of attack near the clear stall point of the clean airfoil with no flap also in the low Reynolds number flow. However, we think that the power performance of GI6 of long flap is slightly lower than that of GI4 and NG0 due to the increase in drag coefficient as shown in Figure 4 and the effect corresponding to applying a camber, in other word, a pitch angle by the flap. While, because GO4 and GO6 (outward facing flaps) have a negative effect on the lift characteristics against GI4 and GI6, these power performances become lower than that of NG0 with no flap in Figure 10 and Figure 11. In addition, we think that the results in the case of large pitch angle 10 degrees in Figure 12 show that GO4 and GO6 can suppress a separation on the blade outward of the rotor comparing with NG0 due to the effect reducing the pitch angle by the outward facing flaps.

Finally, for the pitch angle is -5 degrees shown in Figure 13, when the leading edge side of the blade is tilted toward the inside of the rotor, the power performance under any flap conditions is clearly lower than for the other pitch angle conditions. The results for the pitch angle of -5 degrees are not very meaningful in terms of the performance of the small-scale VAWT, but it shows a clear trend in the relationship between the flap direction and size and the power performance. Therefore, we dare to show Figure 13. The power performance is the highest for GI6 with inward facing and longer flap, followed by GI4, NG0, GO4 and GO6 in that order. In particular, for GO4 and GO6 with outward facing flaps, the power coefficients are almost zero or less. This means the rotation control motor drives the wind turbine rotor and the rotor acts as the fan.

The effect of the Gurney flap on the small-scale VAWT test model used in this study is discussed comparatively based on the results for each of the pitch angle 
conditions shown in Figures 10-13. The addition of the flap has the effect of turning the blade to the side where the flap is attached. In other words, it has the effect of adding a pitch angle, and this effect is proportional to the size of the flap. Therefore, as shown in Figure 13, by adding a long flap (GI6) facing inward of the rotor, even when the pitch angle is -5 degrees, the same effect as turning the blade to have the positive pitch angle is obtained. As a result, it is considered that the power performance is more improved compared to that with no flap.

To further consider the relationship among the flap height and the pitch angle and the power performance for the small-scale VAWT test model, Figure 14 shows the relationships between the maximum power coefficient in the performance curve and the pitch angle for each flap condition shown in Figures 10-13. The vertical axis in Figure 14 is the maximum power coefficient $C p_{\max }$ and the horizontal axis is the pitch angle $\theta$.

As is clear from Figure 14, at the pitch angle of 5 degrees, all four cases except GO6 show the highest maximum power coefficients. For the small-scale VAWT test model, the optimum pitch angle is around 5 degrees. When the pitch angle is less than 5 degrees, the power performance is improved by attaching the Gurney flap on blade inward of the rotor, as shown by GI4 and GI6. However, as shown in Figure 10 and Figure 11, over the entire range of tip speed ratio, the power performance of GI6 with the longer flap is inferior to that of GI4 with the shorter flap. At the large pitch angle of 10 degrees, the relationship between the effect of the Gurney flap and the flap attaching direction is reversed. The power performances of GO4 and GO6 with outward facing flaps are higher than that of NG0 with no flap and the performance of NG0 is improved by the outward facing flaps. From the results shown in Figure 14, it can be said that the pitch angle, at which the relationship between the attaching direction of the Gurney flap and the performance improvement effect is reversed, is between 5 and 10 degrees for the small-scale VAWT used in this study. It should be noted that in terms of the performance of the small-scale VAWT, the influence of the pitch angle on the performance is greater than that of the Gurney flap.

From the above discussion, when applying Gurney flaps to a small-scale

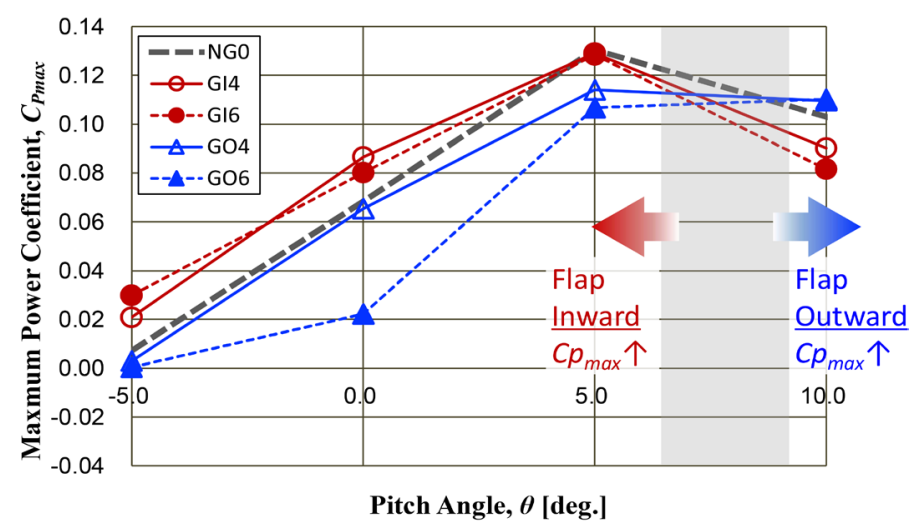

Figure 14. Relationships between maximum power coefficient and pitch angle comparing each Gurney flap condition. 
straight-bladed Darrieus VAWT, it can be said that the pitch angle of the blade showing the highest power performance should first be determined, then the application of Gurney flaps should be considered. Regarding the direction and height of Gurney flap, the flap on the inner side of the rotor is preferable. As for the flap height, from the comparison between flap height $h / c=0.036 \mathrm{~mm}$ and $0.055 \mathrm{~mm}$, a short Gurney flap with $h / c=0.036 \mathrm{~mm}$ is better and is expected to improve the power performance of the small-scale VAWT especially in the low tip speed ratio range.

\section{Summary}

In order to investigate the effect of blade camber direction and pitch angle on the performance of a small-scale straight-blade Darrieus vertical axis wind turbine (VAWT) with symmetrical NACA0018 airfoils, the numerical analysis of the single NACA0018 airfoil with/without the Gurney flap and the performance tests of the VAWT test model by using the Gurney flaps were conducted. The flap heights of $h / c=0.036$ and 0.055 and the flap attachment directions of inward and outward of the rotor were examined. The following conclusions were obtained.

1) Numerical analysis of single NACA0018 airfoil with the Gurney flap used in the VAWT test model shows that the Gurney flap can improve the lift characteristics even in the low Reynolds number region, and $\Delta C_{\text {Lave }}=0.42$ at $h / c=$ 0.036 and $\Delta C_{L \text { ave }}=0.74$ at $h / c=0.055$. The lift enhancing effect of the Gurney flap is maintained up to almost the same angle of attack near the stall point of the clean airfoil with no flap.

2) In terms of the effect of flap height and direction corresponding to the camber effect, especially its direction, on the power performance of the small-scale VAWTs, it is considered that the effective camber direction on the power performance is inward of the rotor when the pitch angle is small and outward when the pitch angle is large. For the small-scale VAWT test model in this study, the results show that the boundary where superiority or inferiority of the power performance is reversed is between the pitch angle 5 and 10 degrees. Furthermore, for the degree of flap height, it is considered that the shorter Gurney flap, in other words, slight camber is effective in improving the power performance of the small-scale straight-blade Darrieus VAWTs.

3) For the small-scale VAWT test model in this study, the optimum pitch angle is about 5 degrees. When the Gurney flap is attached facing inward of the rotor, the power performance is higher than that without flap. For flap heights, the shorter flap $h / c=0.036$ is more effective than $h / c=0.055$. The shorter flap facing inward of the rotor shows good performance improvement effect in the tip speed ratio range lower than where the performance curve reaches its peak.

\section{Conflicts of Interest}

The authors declare no conflicts of interest regarding the publication of this paper. 


\section{References}

[1] Tanino, T., Nakao, S., Miyaguni, T. and Takahashi, K. (2011) Influence of Reynolds Number and Scale on Performance Evaluation of Lift-Type Vertical Axis Wind Turbine by Scale-Model Wind Tunnel Tests. International Journal of Fluid Machinery and Systems, 4, 229-234. https://doi.org/10.5293/IJFMS.2011.4.2.229

[2] Fujikawa, T., Tanino, T. and Takamori, A. (2007) Operating Experience of a Straight Wind Vertical-Axis Type Wind Turbine. Proceedings of 29 th Symposium on Wind Energy Utilization, 29, 338-341. (In Japanese)

[3] Longhuan, D., Grant, I. and Robert, G.D. (2019) Experimental Study of the Effects of Turbine Solidity, Blade Profile, Surface Roughness, and Aspect Ratio on the Darrieus Wind Turbine Self-Starting and Overall Performance. Journal of Energy Science \& Engineering, 7, 2421-2436. https://doi.org/10.1002/ese3.430

[4] Hara, Y., Sumi, T., Wakimoto, M., Kogo, S., Mizuguchi, S., Yoshimi, K. and Akimoto, H. (2014) Comparison between Symmetrical and Cambered Blade Sections for Small-Scale Wind Turbines with Low Center of Gravity. Journal of Fluid Science and Technology, 9, Article No. 13-00325. https://doi.org/10.1299/jfst.2014jfst0006

[5] Ejiri, E. and Iwadate, T. (2017) Influence of Blade Camber of Straight-Blade Vertical Axis Wind Turbine on Flow and Aerodynamic Performance. Transactions of the Japan Society of Mechanical Engineers (JSME), Series B, 83, 16-00484. (In Japanese) https://doi.org/10.1299/transjsme.16-00484

[6] Kirke, B.K. and Lazauskas, L. (1991) Enhancing the Performance of Vertical Axis Wind Turbine Using a Simple Variable Pitch System. Wind Engineering, 15, 186-195.

[7] Zhu, H.T., Hao, W.X., Li, C. and Liu, Q.S. (2019) Numerical Study of Effect of Solidity on Vertical Axis Wind Turbine with Gurney Flap. Journal of Wind Engineering \& Industrial Aerodynamics, 186, 17-31.

https://doi.org/10.1016/j.jweia.2018.12.016

[8] Zhu, H.T., Hao, W.X., Li, C., Luo, S. and Liu, Q.S. (2021) Effects of Geometric Parameters of Gurney Flap on Performance Enhancement of Straight-Bladed Vertical Axis Wind Turbine. Renewable Energy, 165, 464-480. https://doi.org/10.1016/j.renene.2020.11.027

[9] Yan, Y., Avital, E., Williams, J. and Korakianitis, T. (2019) CFD Analysis for the Performance of Gurney Flap on Aerofoil and Vertical Axis Turbine. International Journal of Mechanical Engineering and Robotics Research, 8, 385-392. https://doi.org/10.18178/ijmerr.8.3.385-392

[10] Boutilier, M.S.H. and Yarusevych, S. (2012) Effects of End Plates and Blockage on Low-Reynolds-Number Flows over Airfoils. Journal of Amrican Institute of Aeronautics and Astronautics, 50, 1547-1559. https://doi.org/10.2514/1.J051469

[11] Myose, R., Heron, I. and Papadakis, M. (1996) The Post-Stall Effect of Gurney Flaps on a NACA-0011 Airfoil. SAE International Journal of Aerospace, 105, 173-178. https://doi.org/10.4271/961316 


\section{Nomenclature}

$A=$ Rotor swept area

$\mathrm{AOA}=$ Angle of attack

$c=$ Airfoil chord length

$C_{D}=$ Drag coefficient

$C_{L}=$ Lift coefficient

$C_{P}=$ Power coefficient

$C_{P \max }=$ Maximum power coefficient

$D=$ Rotor diameter

$h=$ Height of Gurney flap

$L=$ Blade length

$r=$ Rotor radius

$\mathrm{Re}=$ Reynolds number

$T=$ Rotor shaft torque

$V=$ Inlet velocity

$\Delta C_{D}=$ Drag coefficient Increment

$\Delta C_{D \text { ave }}=$ Time averaged drag coefficient Increment

$\Delta C_{L}=$ Lift coefficient Increment

$\Delta C_{L \text { ave }}=$ Time averaged lift coefficient Increment

$\theta=$ Blade pitch angle

$\lambda=$ Tip speed ratio

$\rho=$ Air density

$\omega=$ Rotation angular velocity 